\title{
渦制御を目的とした渦流の増速及び減速機構 の円筒渦室内の気流の周分速度の評価
}

\section{Estimation of Tangential Velocity of Gas Flow in Vortex Chamber for Co-Rotating and Counter-Rotating Flow Systems for Vortex Control}

\author{
○小川 明 (日大工)、大野 努 (日大工、学)、岡部 隼人 (日大工、学)、 \\ 大八木 健人 (日大工、学)、秋葉 典明 (日大工、学) \\ Akira Ogawa, Dept.Mech.Eng., College of Eng., Nihopn Univ., Kooriyamashi, Tamura-machi \\ Tzutomu Oono, Dept.Mech.Eng., College of Eng., Nihopn Univ., Kooriyamashi, \\ Hayato Okabe,Dept.Mech.Eng.,College of Eng., Nihopn Univ., Kooriyamashi, \\ Taketo Ooyagi,Dept.Mech.Eng., College of Eng., Nihopn Univ., Kooriyamashi, \\ Noriaki Akiba,Dept.Mech.Eng., College of Eng., Nihopn Univ., Kooriyamashi,
}

Key Words: Co-Rotating and Counter Rotating Flow Systems, Vortex Chamber, Tangential Velocity

1 はじめに

渦流制御のための円筒渦室の構造として、渦流の周分速度 を増幅するための機構として、渦室の外筒に接線的に一次及 び二次気流の流入管を渦室内の気流が相互に加速する構成、 これを Co-Rotating Flow System(Co-R-F-S) と名付け、渦室内 の気流が相互に対向する方向にこれらを設置する構成、これ を Counter-Rotating Flow System (C-R-F-S) と名付け、圧力損 失と気流の周分速度及び軸分速度分布の測定した。Co-R-F-S の場合には、筆者の一人は既に二次気流形サイクロン分離器

(Drehströmungsentstauber) により、含塵旋回気流の 主流に対して二次気流の効果が圧力損失と分離性能に如何に 拘わるか報告した。一方、C-R-F-S の場合では、両者の工ネ ルギーが同一の場合、角運動量の相互の相殺により、旋回流 が渦室中央領域でほぼ零となり、その上下領域では相互の回 転流動を維持している。これに対し、両者の内、流入エネル ギーの高い気流の回転方向に渦室内の全体の旋回気流が従う 結果が得られた。そこで、この旋回気流の流体力学的特性を 考察するための主要要素として、気流の周分速度分布の評価 について報告する ${ }^{(1,2,3,4)}$ 。

2 基本式の誘導

2. 1 外筒壁近傍の周分速度

2.1.1 Co-Rotating Flow System $の$ 場合

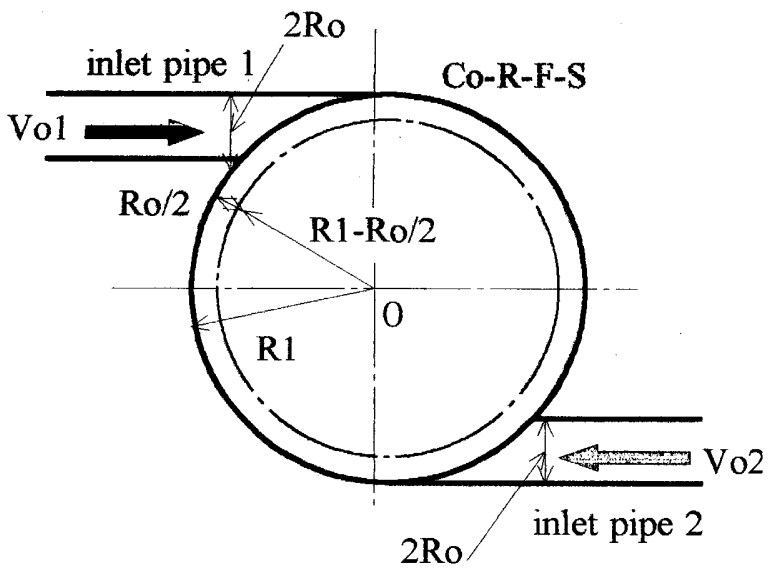

Fig.1 Schematic illustartion of Co-Rotating Flow System

外筒壁近傍の周分速度 Voi $(\mathrm{m} / \mathrm{s})$ は、Fig.1 に示したよう に、入口管 1 と 2 から流入した角運動量が加算され、壁面摩 擦を無視し、断面積 $\mathrm{Hi} \cdot \mathrm{Ro} / 2\left(\mathrm{~m}^{2}\right)$ を回転速度 Voi で旋回す るとみなし、次式が得られる。

$\rho \cdot Q_{1} \cdot V_{01} \cdot\left(R_{1}-R_{0}\right)+\rho \cdot Q_{2} \cdot V_{02} \cdot\left(R_{1}-R_{0}\right)=\rho \cdot\left(R_{0} / 2\right) \cdot H i \cdot V_{0 i} \cdot V_{0 i} \cdot\left(R_{1}-R_{0} / 2\right)$
これより、上式を変形して次式を得る。

$\frac{V_{0 i}}{V_{0 e}}=\frac{V_{0 i}}{\sqrt{V_{01}^{2}+V_{02}^{2}}}=2 \times \sqrt{\frac{\pi \cdot R_{0} \cdot\left(R_{1}-R_{0}\right)}{H i \cdot\left(2 \times R_{1}-R_{0}\right)}}$

上式に、円筒渦室構造の寸法を代入して次式となる。 $\mathrm{Voi} / \mathrm{Voe}=0.677$.

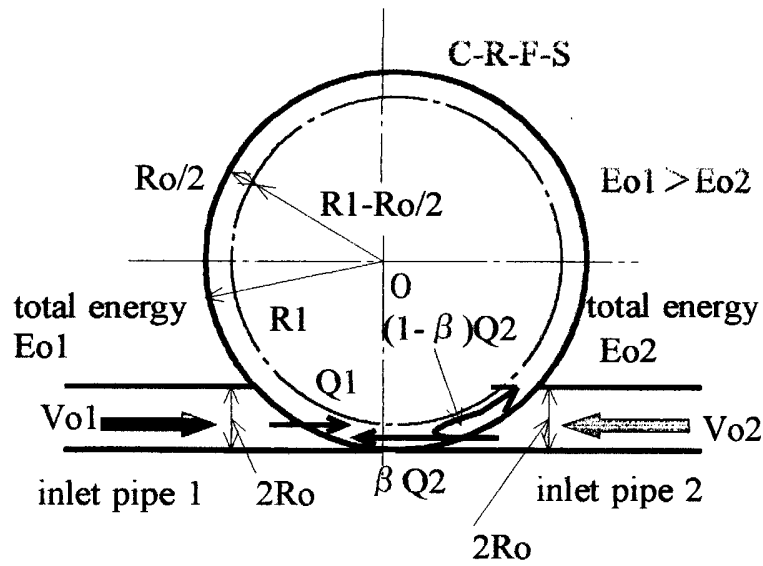

Fig.2 Schematic illustration of Counter-Rotating Flow System

2.1.2 Counter-Rotating Flow. System の場合

$\mathrm{E} 1>\mathrm{E} 2$ の条件

この条件の時、Fig.2 に示すように、流入管 2 から流入する 流量 Q2 のうち、分量係数 $\beta$ として、 $\beta$ Q2 がそのまま対 抗流入する流体と衝突し、残りの $(1-\beta)$ Q2 は反転して 外筒壁面に沿い回転すると仮定する。但し、 $0 \leqq \beta \leqq 1$ の条 件である。これより、入口管 1 から流入する回転方向を正と すれば次式が得られる。

$\rho \cdot Q_{1} \cdot V_{01} \cdot\left(R_{1}-R_{0}\right)-\beta \cdot Q_{2} \cdot \rho \cdot V_{02} \cdot\left(R_{1}-R_{0}\right)+\rho \cdot(1-\beta) \cdot Q_{2} \cdot V_{02} \cdot\left(R_{1}-R_{0}\right)=$

$=\rho \cdot\left(R_{0} / 2\right) \cdot H i \cdot V_{0 i} \cdot V_{0 i} \cdot\left(R_{1}-R_{0} / 2\right)$

ここに、分量係数 $\beta$ は、次式で定義されると仮定する。

$\beta=\left(V_{02} / V_{01}\right)^{2}$

従つて、次式を得る。

$\frac{V_{0 i}}{V_{0 e}}=\sqrt{\frac{4 \times \pi \cdot R_{0} \cdot\left(R_{1}-R_{0}\right)}{H i \cdot\left(2 \times R_{1}-R_{0}\right)}} \cdot \sqrt{\frac{\left\{1-\left(V_{02} / V_{01}\right)^{2}\right\} \cdot\left\{1+2 \times\left(V_{02} / V_{01}\right)^{2}\right\}}{\left\{1+\left(V_{02} / V_{01}\right)^{2}\right\}}}$ 
これに渦室の寸法を代入すると次式が得られる。

$\frac{V_{0 i}}{V_{0 e}}=0.677 \times \sqrt{\frac{\left\{1-\left(V_{02} / V_{01}\right)^{2}\right\} \cdot\left\{1+2 \times\left(V_{02} / V_{01}\right)^{2}\right\}}{\left\{1+\left(V_{02} / V_{01}\right)^{2}\right\}}}$

$\mathrm{E} 1<\mathrm{E} 2$ の条件

この場合、一次気流の分量係数 $\gamma$ とすれば、 $\gamma \mathrm{Q} 1$ が対向流 量となり、(1- $\gamma)$ Q1 が反転して渦室外筒壁面に沿い、二次 気流と同一の回転流動するとみなせば、次式が得られる。 $\rho \cdot \gamma \cdot Q_{1} \cdot V_{01} \cdot\left(R_{1}-R_{0}\right)-\rho \cdot(1-\gamma) \cdot Q_{1} \cdot V_{01} \cdot\left(R_{1}-R_{0}\right)-\rho \cdot Q_{2} \cdot V_{02} \cdot\left(R_{1}-R_{0}\right)=$

$=\rho \cdot\left(R_{0} / 2\right) \cdot H i \cdot V_{0 i} \cdot V_{0 i} \cdot\left(R_{1}-R_{0} / 2\right)$

ここで、分量係数 $\gamma$ として、次式を仮定する。

$\gamma_{-}=\left(2-\frac{V_{02}}{V_{01}}\right)^{2} \quad(0 \leqq \gamma \leqq 1)$

eq. (7) より、次式を得る。

$\frac{V_{0 i}}{V_{0 e}}=-\sqrt{\frac{4 \times \pi \cdot R_{0} \cdot\left(R_{1}-R_{0}\right)}{H i \cdot\left(2 \times R_{1}-R_{0}\right)}} \cdot \sqrt{1-\frac{2 \times\left(2-V_{02} / V_{01}\right)^{2}}{\left\{1+\left(V_{02} / V_{01}\right)^{2}\right\}}}$

これに渦室の寸法を代入して次式を得る。

$\frac{V_{0 i}}{V_{0 e}}=-0.677 \times \sqrt{\frac{2 \times\left(2-V_{02} / V_{01}\right)^{2}}{\left\{1+\left(V_{02} / V_{01}\right)^{2}\right\}}}$

これらの関係を表せば、Fig.3 となる。同図には、Voi=25.0m/s 一定亡した条件の下で、Vo2 $=0,5,15$ and $25 \mathrm{~m} / \mathrm{s}$, 測定位置 $Z=2,6$ and 10 の測定結果を、Co-R-F-S 及び C-R-F-S につい て、それぞれ示した。壁面摩擦を無視したにも拘わらず、比 較的両者の相関は良い。ここに、Voe $(\mathrm{m} / \mathrm{s})$ は、次式で定義 した入口管流入速さである。

$V_{o e}=\sqrt{V_{01}^{2}+V_{02}^{2}}$

\section{2 周分速度の最大值の評価}

ついで、周分速度の最大值 $\mathrm{V} \theta \max (\mathrm{m} / \mathrm{s})$ は、Ogawa の組 み合わせ渦モデル(5)を用いて、次式のように得られる。但 し、周分速度の最大值の半径位置 は、 $\mathrm{a}=(2 / 3) \times \mathrm{R} 2$ と办 なす。但し、この渦室の両出口管が大気開放の条件であり速 度係数 $\mathrm{Kv}(1)$ は、 $\mathrm{Kv}=0.805$ と仮定する。

$\frac{V_{\theta \max }}{V_{o i}}=K v \cdot \frac{1}{4} \times\left(\frac{3}{8} \times \frac{2 \cdot R_{1}-R_{0}}{R_{2}}\right)^{n} \times(2+n) \cdot\left(\frac{2+n}{1+n}\right)^{(1+n)}$

上式に主要寸法を代入すれば、速度指数 $\mathrm{n}(1)$ に対して Fig.4を得る。Fig.5 は、eq.(11) を用いて計算したV $\theta$ max と上述の条件による、直径 $\mathrm{Dl}=150 \mathrm{~mm}, 2$ 本の入口管径

$\mathrm{Do}=24 \mathrm{~mm}$, 出口管径 $\mathrm{D} 2=50 \mathrm{~mm}$, 円筒高さ Hi150mm の透明 なアクリル樹脂加工の内面の滑らかな渦室に、円筒形ピト 一管を用いて測定した結果との比較である。Vol $=25 \mathrm{~m} / \mathrm{s}$ 一定 で、Z=6におけるnの值は、Co-R-F-S の場合、Vo2 $=0 \mathrm{~m} / \mathrm{s}$, $\mathrm{Rec}=5024, \mathrm{n}=0.8 ; \mathrm{Vo} 2=5 \mathrm{~m} / \mathrm{s}, \operatorname{Rec}=6029, \mathrm{n}=0.8 ; \quad \mathrm{Vo} 2=15 \mathrm{~m} / \mathrm{s}$, $\operatorname{Rec}=8034, \mathrm{n}=1.0 ; \quad \mathrm{Vo} 2=25 \mathrm{~m} / \mathrm{s}, \quad \operatorname{Rec}=10048, \mathrm{n}=0.92$ である。 C-R-F-S では、 $\mathrm{Vo} 2=0 \mathrm{~m} / \mathrm{s}, \mathrm{n}=0.9 ; \quad \mathrm{Vo} 2=5 \mathrm{~m} / \mathrm{s}, \mathrm{n}=0.8$; $\mathrm{Vo} 2=15 \mathrm{~m} / \mathrm{s}, \mathrm{n}=0.6 ; \mathrm{Vo} 2=25 \mathrm{~m} / \mathrm{s}, \mathrm{n}=0$ である。計算值と実験結 果は平均的には比較的良い相関を示した。

\section{3. まとめ}

（1）筆者の一人は、角運動量の遷移過程の理論解析から、 気流の周分速度の加速過程の Spin-up timeについて検討した (6) Co-R-F-S の場合に比較して、C-R-F-S の場合では、一
次気流と二次気流の全エネルギーの大小により、その大きい エネルギーの回転方向に旋回流動している。但し、両者が等 しい時は、渦室の中央断面を境として、ほぼ上下対称に据れ るように流動している。

(2) Fig.3に示したように、円筒渦室外筒壁面近傍の Voi/Voe の壁面摩擦を無視した計算值と実験值との比較から、eq. (2) と eq. (5)による值は、定性的には評価できる。

(3) eq. (11) によるV $\theta$ max とVoe との関係は、Fig.5 に実験値との比較として示したように、定性的なは評価でき るが、C-R-F-S の場合、速度指数 $\mathrm{n}$ を見積る方法を検討する 必要がある。また、一次気流と二次気流の流入速度による圧 力損失に関しては、文献（7）に詳述する。

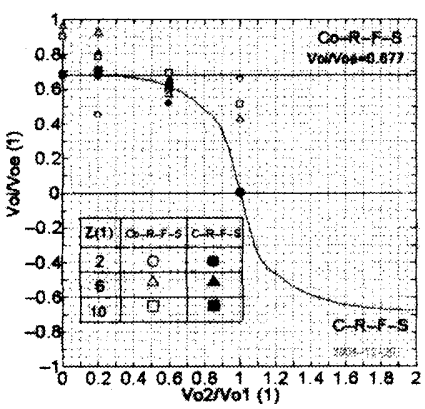

Fig. 3 Correlation between Voi/Voe and Vo2/Vol

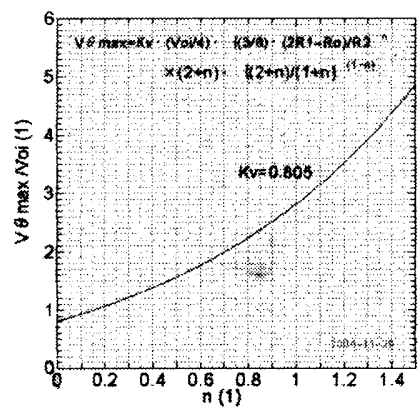

Fig.4 Estimation of the maximum tangential velocity

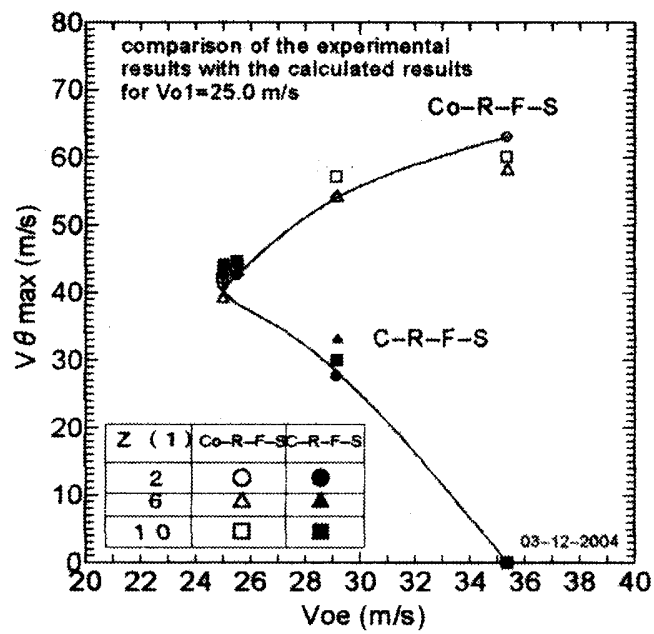

Fig.5 Comparison of the maximum tangential velocity of the experimental results with the calculated results by eq. (11)

\section{引用文献}

(1) Winkler,A.R.,Ogawa,K,Oono,W,Sinya,S,Washizu,M A.Ogawa,; J.College of Eng.,Nihon Univ., Vol.45,No.2(2004) .March, P.61 P.74.

(2) 小川明、小川和靖、大野涉、新屋誠一、鷲頭雅晴、 A. R。 ヴィンクラー; 日本機械学会東北支部第 40 期秋季講演 会(秋田県立大学システム科学技術学部)、平成 16 年 9 月 1 7 日 No.041-2,P.109 P.110.

（3）小川明、秋庭典明、大野努、大八木健人、岡部隼人; 2004 年精密工学会東北支部学術講演会、講演論文集、2004 年 12 月 4 日（日本大学工学部）、P. $27 \sim$ P. 28 .

(4) 岡部隼人、大野努、秋庭典明、大八木健人、小川明、 ; 2004 年精密工学会東北支部学術講演会、講演論文集、 2004 年 12 月 4 日 (日本大学工学部)、P.29 P. 30 .

(5) Ogawa,A.; Vortex Flow, CRC-Press (1993)

( 6) Ogawa,A.,Murakami,H.,J.Thermal Science, Vol.13,No.1 (2004), P.46 P.55.

(7) Ogawa,A.,Winkler,A.R,Oono.T,Okabe,H.,Ooyagi,T.,Akiba,N, ; J.College of Eng.,Nihon-U., Vol.46, No.2 (2005-Marcb). 